Original Article

\title{
Effect of exhalation exercise on trunk muscle activity and oswestry disability index of patients with chronic low back pain
}

\author{
Jeong-Il Kang, PT, PhD ${ }^{1)}$, Dae-Keun Jeong, PT, PhD ${ }^{1)^{*}}$, Hyun Chol, PT, PhD ${ }^{2)}$ \\ 1) Department of Physical Therapy, Sehan University: 1113 Noksaek-ro, Samho-eup, Youngam-gun, \\ Jeonnam 526-702, Republic of Korea \\ 2) Department of Physical Therapy, Mokpo Mirae Hosipital, Republic of Korea
}

\begin{abstract}
Purpose] This study investigated the effect of exhalation exercises on trunk muscle activity and Oswestry Disability Index by inducing trunk muscle activity through increasing intra-abdominal pressure and activating muscles, contributing to spinal stability. [Subjects and Methods] This intervention program included 20 male patients with chronic low back pain. A total of 10 subjects each were randomly assigned to an exhalation exercise group as the experimental group and a spinal stabilization exercise group as the control group. [Results] There were significant differences in the activities of the rectus abdominis, transverse abdominis, external oblique abdominal, and erector spinae muscles as well as in the Oswestry Disability Index within the experimental group. There were meaningful differences in the activities of the rectus abdominis, external oblique abdominal, and erector spinae muscles and in the Oswestry Disability Index within the control group. In addition, there was a meaningful intergroup difference in transverse abdominis muscle activity alone and in the Oswestry Disability Index. [Conclusion] The breathing exercise effectively increased muscle activity by training gross and fine motor muscles in the trunk. Moreover, it was verified as a very important element for strengthening body stability because it both released and prevented low back pain.

Key words: Breathing exercise, Chronic low back pain, Trunk muscle activity
\end{abstract}

(This article was submitted Jan. 19, 2016, and was accepted Feb. 22, 2016)

\section{INTRODUCTION}

Low back pain (LBP) is a representative musculoskeletal disease with a current prevalence of $60-90 \%$; more than $80 \%$ people will experience LBP at least once in their lifetime. Among them, approximately $15 \%$ have from chronic $\mathrm{LBP}^{1)}$.

LBP occurs when a poor lifestyle weakens the muscular strength of the waist and excessive loads on and tensions of the muscles create pain. Mediating muscle weakening to stabilize the trunk is an important aspect in the recovery of body function in patients with $\mathrm{LBP}^{2}$. Structural changes of the waist muscles and histomorphological changes lead to chronic LBP; in particular, weakening and atrophy is more common in the muscle fibers that stabilize the waist ${ }^{3)}$. In addition, if pain develops in the muscles, weakening and atrophy will occur, the ligaments and joints will become stiff, and activity will decrease. A vicious circle of worsening pain repeats by muscle rigidity and sprain ${ }^{4}$. Therefore, it is important to maintain mechanical alignment of the trunk muscles to prevent LBP. It is necessary to keep an upright pattern of muscle activity as well as proper muscle length and strength ${ }^{5}$. Intra-abdominal pressure that is produced by the connection of trunk stabilization and respiratory muscles affects waist stability and protects the trunk muscles ${ }^{6}$. Effective mediation is reportedly accomplished using simultaneous breathing exercises to relax excessive muscle tension ${ }^{7)}$. In addition, if intra-abdominal pressure increases by diaphragm stimulating activity by performing breathing exercises, even the pelvic floor muscles will be activated. As such,

*Corresponding author. Dae-Keun Jeong (E-mail: dklovept@naver.com)

(C2016 The Society of Physical Therapy Science. Published by IPEC Inc.

This is an open-access article distributed under the terms of the Creative Commons Attribution Non-Commercial No Derivatives (by-nc-nd) License $<$ http://creativecommons.org/licenses/by-nc-nd/4.0/>. 
contraction of the abdominal muscles during breathing can easily activate even the deep stabilization muscles ${ }^{8)}$. Clinicians recognize that stabilization exercises to strengthen the waist and abdominal muscles are very important. Mediating breathing exercise activates the trunk muscles more effectively and decreases LBP. As such, this study intended to induce activity of the trunk muscles that contribute to spinal stabilization and increase intra-abdominal pressure by performing exhalation exercises as well as to investigate the effects on trunk muscle activity and Oswestry Disability Index (ODI) by comparing spinal stabilization and exhalation exercises. We intend to utilize this exercise method to effectively treat lumbar pain in the future.

\section{SUBJECTS AND METHODS}

Subjects were 20 male patients (age 31-45 years) with chronic LBP who visited B hospital located in Jeollanamdo, South Korea, and complained of LBP over 12 weeks. Patients with acute pain, continuous severe pain, spondylolysis, or spondylolisthesis were excluded from the study. Those who had paresthesia, myoparalysis, or psychological problems as well as those who had difficulty in performing exercise due to lack of comprehension were also excluded. Subjects who understood the purpose of this study and consented to participate were selected (Table 1).

This study was approved by the Bioethics Committee of Sehan University Center (approval number: 2015-7).

This study included 20 male patients with chronic LBP, and 10 subjects each were randomly allocated to the exhalation exercise group (experimental group) and trunk stabilization group (control group). The intervention program consisted of daily 30-minute sessions once daily 4 times a week for 6 weeks. The trunk muscle activities and ODI were calculated, compared, and analyzed before versus after the intervention program by using surface electromyography (sEMG).

A surface electromyography (EMG) MP 100 system (Biopac system inc, Goleta, USA) was used to measure trunk muscle activities, with a sampling rate of $1,000 \mathrm{~Hz}$. The frequency band-pass filter was set at $20-450 \mathrm{~Hz}$. Each subject's hair was removed and dead skin cells were removed using a thin sandpaper to minimize skin resistance to the EMG signal. The skin was then cleaned with alcohol-soaked cotton. Two $\mathrm{Ag} / \mathrm{AgCl}$ surface electrodes were attached to the belly of each muscle in a direction parallel to the muscular fiber at 2-cm intervals. Standard electrodes were attached to the spinous process of the 12th thoracic vertebrae and scapula spine. The EMG signals of the right rectus abdominis, transverse abdominis, external oblique abdominis, and erector spine muscles were collected. The sampling rate for the EMG signal collection was set to 1,000 $\mathrm{Hz}$, the notch filter was set to $60 \mathrm{~Hz}$, and the band pass filter was set to $20-450 \mathrm{~Hz}$. The signals were converted to root mean square (RMS) values, and an EMG signal analysis was conducted using Acqknowledge 3.9.1 software (Biopac). EMG data were collected while the subjects were performing the stabilization exercise and 6 of the 10 seconds were used.

Maximal voluntary isometric contraction (MVIC) was used to standardize the EMG signal during the stabilization exercise $^{9)}$. The MVIC of the rectus abdominis muscle was measured in the knee-bent position, with both arms on the chest and the trunk bent at $45^{\circ}$ at maximum resistance. The MVIC of the transverse abdominis muscle was measured in the knee-bent position, with both arms on the chest and during sit-ups, twisting the trunk from left to right at maximum resistance ${ }^{10)}$. The MVIC of the external oblique abdominis muscles was measured while rotating the trunk to opposite side with the trunk bending, while the MVIC of the erector spinae muscles was measured in a prone position, with both hands on back of the head and the trunk extended at maximum resistance ${ }^{11}$. MVIC was measured when the researcher made the subjects perform isometric contraction maximally while a beep was played for 5 seconds. The first and last seconds of the measurements were excluded; thus, a 3-second measurement was analyzed. The researcher continuously encouraged subjects to maintain a maximum contraction and the percentage value of the muscle was the highest average value of 3 measurements. The subjects were given a 30 -second rest after the MVIC of each muscle was measured ${ }^{12}$.

The ODI was measured using the Korean version of the ODI to quantify physical difficulties in daily life due to LBP (Cronbach's alpha $=0.92$ ). The original ODI is composed of 10 items evaluated as $0-5$ points (low to high severity). In the Korean ODI, considering the Korean culture, the item about sex life was excluded, so a total of 9 items were evaluated (for a highest possible score of 45). The total score was divided by number of items $\times 5$ and was expressed as a percentage ${ }^{13)}$.

A trunk stabilization exercise, the modifying exercise method of Urquhart et al. ${ }^{14)}$ and Steven et al. ${ }^{15)}$, which consists of 3 stages $^{16)}$, was used. The steps consist of awareness, associative, and exercise task. The exercise was performed for 30 minutes a session 4 times a week for 6 weeks at an intensity acceptable to each subject (Table 2).

Table 1. Subjects' characteristics

\begin{tabular}{lcc}
\hline Items & $\begin{array}{c}\text { Experimental group } \\
(\mathrm{n}=10)\end{array}$ & $\begin{array}{c}\text { Control group } \\
(\mathrm{n}=10)\end{array}$ \\
\hline Age (years) & $42.5 \pm 5.3$ & $40.1 \pm 5.3$ \\
Height $(\mathrm{cm})$ & $168.5 \pm 5.7$ & $166.3 \pm 4.9$ \\
Weight $(\mathrm{kg})$ & $64.3 \pm 9.8$ & $65.4 \pm 8.2$ \\
ODI (points) & $26.2 \pm 4.2$ & $25.3 \pm 3$ \\
\hline
\end{tabular}

${ }^{\mathrm{a} M e a n} \pm \mathrm{SD}$, Shapiro-Wilk test.

ODI: Oswestry Disability Index 
The bracing exercise was performed for 20 minutes a session, 5 times a week, for 6 weeks in the group training the exhalation muscles ${ }^{17}$ ). In this exercise method, the subjects bent their knees at $90^{\circ}$ and adjusted the alignment of their waist and pelvis in supine position. A biofeedback system was then attached to the waist and pressure was maintained at $40 \mathrm{mmHg}$. The pressure of the manometer increased from $40 \mathrm{mmHg}$ to $70 \mathrm{mmHg}$ and was maintained by quick contractions of the abdominal muscles by the application of abdominal strain. This exercise was intended to be performed with the feeling that the trunk muscles spread outward and the rectus abdominis muscles did not bulge while the subjects were able to breathe easily ${ }^{17)}$.

SPSS 18.0 for Windows was used to process the data and the Shapiro-Wilk test was used to test the normality of the subjects' general characteristics, respiratory muscle activities, and body functions of the groups. A paired t-test was used to compare intragroup changes, while analysis of covariance was used to compare intergroup changes. Significance level was set at $\alpha=0.05$.

\section{RESULTS}

There were significant differences in the rectus abdominis, transverse abdominis, external oblique abdominal, and erector spinae muscle activation and in the ODI within the experimental group ( $<<0.05$ and $<0.001$, respectively). There were significant differences in the rectus abdominis muscle, external oblique abdominal muscle, erector spinal muscle and ODI within control group $(\mathrm{p}<0.05)$. In addition, there was a meaningful difference in the transverse abdominis muscle alone on comparing the change in trunk muscle activity and in ODI between the groups $(\mathrm{p}<0.05)($ Table 3$)$.

Table 2. Trunk muscle stabilization intervention exercise program

\begin{tabular}{|c|c|c|c|c|}
\hline Stage & Time & Contents & \multicolumn{2}{|l|}{ Program } \\
\hline $\begin{array}{l}\text { Warming-up } \\
\text { exercise }\end{array}$ & $5 \mathrm{~min}$ & $\begin{array}{l}\text { Flexibility } \\
\text { whole-body exercise }\end{array}$ & \multicolumn{2}{|c|}{ Upper-lower extremity stretching and joint moving exercise } \\
\hline \multirow{7}{*}{ Main exercise } & \multirow{7}{*}{$20 \mathrm{~min}$} & \multirow{7}{*}{$\begin{array}{l}\text { Trunk muscle } \\
\text { stabilization } \\
\text { exercise }\end{array}$} & & 1) Pelvic posterior tilting in a supine position with both knees flexed \\
\hline & & & Stage 1 & 2) Abdominal draw-in in a supine position with both knees flexed \\
\hline & & & & 3) Pelvic anterior tilting in a supine position with both knees extended \\
\hline & & & & 4) Abdominal draw-in in a supine position with both knees extended \\
\hline & & & Stage 2 & 5) Bridging in supine position \\
\hline & & & \multirow{2}{*}{ Stage 3} & 6) Ball bridge \\
\hline & & & & 7) Unstable bridging: bridging with extension of the left/right leg \\
\hline $\begin{array}{l}\text { Cool-down } \\
\text { exercise }\end{array}$ & $5 \mathrm{~min}$ & $\begin{array}{l}\text { Aerobic } \\
\text { exercise }\end{array}$ & \multicolumn{2}{|c|}{ Breathing with abdominal muscles } \\
\hline
\end{tabular}

Table 3. Comparison of change of muscle activity and ODI within each group and between the groups

\begin{tabular}{lclcc}
\hline & & Group & Pre & Post \\
\hline & \multirow{2}{*}{ RA } & Experimental group & $21.3 \pm 5.1^{\mathrm{a}}$ & $25.6 \pm 4.2^{*}$ \\
& & Control group & $21.6 \pm 5.2$ & $25.8 \pm 4.3^{*}$ \\
& \multirow{3}{*}{ TARVC } & Experimental group & $16.2 \pm 2.4$ & $19.4 \pm 3.1^{*}$ \\
& & Control group & $14.3 \pm 3.2$ & $15.7 \pm 3.6$ \\
& \multirow{2}{*}{ EAO } & Experimental group & $16 \pm 2.5$ & $20.2 \pm 2.1^{*}$ \\
& & Control group & $17.3 \pm 3.2$ & $21 \pm 3.5^{*}$ \\
& \multirow{2}{*}{ ES } & Experimental group & $23 \pm 6.49$ & $28.2 \pm 6^{*}$ \\
& & Control group & $26 \pm 5.19$ & $29.1 \pm 4.9^{*}$ \\
& & Experimental group & $27.1 \pm 2.7$ & $23.2 \pm 1.9^{* *}$ \\
& & Control group & $28.2 \pm 2.7$ & $26.2 \pm 1.7^{*}$ \\
\hline
\end{tabular}

$* \mathrm{p}<0.05, * * \mathrm{p}<0.001$.

${ }^{a}$ Mean \pm SD, paired t-test, analysis of covariance.

RA: rectus abdominis muscle; TA: transverse abdominis muscle; EAO: external abdominal oblique muscle; ES: erector spinae muscle; ODI: Oswestry Disability Index 


\section{DISCUSSION}

Recently, Interest in the use of breathing exercises such as abdominal respiration and yoga breathing to improve vertebral joint stability and motor control is increasing ${ }^{18)}$. Hodges et al. ${ }^{3)}$ found that the respiratory muscles are an important factor affecting spinal stabilization. In particular, if respiratory and abdominal muscle activities are uncertain, spinal stabilization will decrease due to decreased intra-abdominal pressure.

Urquhart et al. ${ }^{19)}$ reported that activities of the deep abdominal muscles should be evoked using a combination of breathing and stabilization exercises rather than stabilization exercises alone. Marshall et al. ${ }^{20)}$ classified 20 patients with nonidiopathic LBP into a stabilization exercise group with abdominal respiration exercise $(\mathrm{n}=10)$ and a general exercise group $(n=10)$ and compared their muscle activity and range of motion. The muscle activities of the abdominal rectus, external oblique abdominis, and erector spinae muscle increased, as did range of motion of the waist. This study's findings support advanced research by drawing a conclusion that the activities of the rectus abdominis, transverse abdominis, external oblique abdominis, and erector spinae muscles increased in the experimental group performing breathing exercises. There was a meaningful intergroup difference in the transverse abdominis alone, in terms of the change of trunk muscle activities. The transversus abdominis muscle is located in the deepest part of the abdomen and is called the corset muscle because it plays a role in stabilizing the waist and creating abdominal pressure owing to being attached to the thoracolumbar fascia. Of all of the abdominal muscles, the transverse abdominis has the widest and closest attachment to the thoracolumbar fascia. As such, it is essential to spinal stability.

$\mathrm{Ki}$ and $\mathrm{Heo}^{21)}$ classified 24 patients with chronic LBP into a spinal stabilization exercise with feedback respiratory exercise group and a trunk stabilization exercise group that they performed 30-45 minutes a session, 3 times a week, for 6 weeks. The spinal stabilization exercise with feedback respiratory exercise increased stability of the vertebral joints and flexibility of the thoracic vertebrae more than the spinal stabilization exercise only. Ferreira et al. ${ }^{22}$ reported that improvement in transverse abdominis muscle activity was higer after postural control exercise than after conventional physiotherapy, targeting 34 patients with chronic LBP. In particular, those findings supported ours since they showed that the transverse abdominis muscle plays an important role in controlling vertebral shearing force.

However, Yoon et al. ${ }^{23}$ ) studied 10 patients with chronic LBP who performed 3 types of stabilization exercises in the quadrupedal position for 20 minutes and then compared trunk muscle activities. The activities of the back muscles of the trunk showed a higher increase in the group in which a hand and a foot were asymmetrically lifted in the quadrupedal position than in the group in which a hand was lifted in the quadrupedal position or in the group which a foot was lifted in the quadrupedal position. However, there was no $\mathrm{P}$ value for the abdominal muscle activities. That finding was opposite those of this study. This study induced abdominal muscle activities using exhalation exercises. However, advanced studies have limited ability to induce abdominal muscle contractions because most agonists were back muscles of the trunk when the stabilization exercise was performed in various quadrupedal positions. Niemisto et al. ${ }^{24}$ found that ODI in the trunk stabilization exercise group decreased meaningfully when trunk stabilization exercise and conventional physiotherapy were mediated in 203 subjects with chronic LBP for 3-12 months. Sung ${ }^{25)}$ found that ODI decreased meaningfully after mediating spinal stabilization exercise for 4 weeks in 16 subjects with chronic LBP. Kang and Jeong ${ }^{26}$ ) found that ODI decreased in a spinal stabilization exercise group as a result of mediating spinal stabilization exercises for 34 patients with chronic LBP for 4 weeks. This study drew a conclusion supporting advanced research because there were meaningful differences in ODI. The reason for this is that the delivery of stimulation on pain receptor tissues such as those around the spine and articular capsules and ligaments decreases as trunk stabilization and breathing exercises strengthen the deep stability muscles and it affects abdominal muscle functional recovery. We found that they are effective to functional disability of LBP by decreasing the delivery of stimulation to the pain receptor tissue such as that around the spine and articular capsules and ligaments. Son ${ }^{27)}$ found a disability index change, center of body gravity change, and area decrease in both a spinal stabilization exercise group with abdominal respiration and a spinal stabilization exercise group; however, no intergroup change was seen. Regardless, there was a meaningful difference in this study in direct opposition to that of advanced research. Abdominal respiration mediation in advanced research is a type of breathing exercise used in the resting state. On the other hand, exhalation exercise is more effective at reducing ODI because compensation in the lumbar region decreases largely as back and waist mobility increase. Breathing exercises effectively increase muscle activity due to training of the gross and fine muscles of the trunk. Since it strengthens the muscles that stabilize the body, the breathing exercise proved to be a very important element as it relieves LBP, prevents lumbar pain, and prevents recurrence. Future studies of deep muscle strengthening are needed to confirm our results.

\section{ACKNOWLEDGEMENT}

This study was supported by the SehanUniversity Research Fund in 2016. 


\section{REFERENCES}

1) Lee CW, Kim HS, Lee IS: The effect of horse-riding exercise on the balance ability in the chronic low back pain patients. J Korean Soc Integr, 2014, 2: 101-108. [CrossRef]

2) Kang JI, Jeong DK: The effect of pelvic stability exercise program on pain and hip joint of patients with chronic low back pain involving sacroiliac joint pain The Korea Society of Digital Policy and Management, 2013, 11: 331-338.

3) Hodges PW, Eriksson AE, Shirley D, et al.: Intra-abdominal pressure increases stiffness of the lumbar spine. J Biomech, 2005, 38: 1873-1880. [Medline] [CrossRef]

4) Huang Q, Li D, Zhang Y, et al.: The intervention effects of different treatments for chronic low back pain as assessed by the thickness of the musculus transversus abdominis. J Phys Ther Sci, 2014, 26: 1383-1385. [Medline] [CrossRef]

5) Kim SJ, Ha SM, Park GN, et al.: Effects of three lumbar stabilization exercises on the thickness of deep and superficial fibers of the lumbar multifidus. PhysTher Korea, 2012, 19: 20-28. [CrossRef]

6) Pulkovski N, Mannion AF, Caporaso F, et al.: Ultrasound assessment of transversus abdominis muscle contraction ratio during abdominal hollowing: a useful tool to distinguish between patients with chronic low back pain and healthy controls? Eur Spine J, 2012, 21: S750-S759. [Medline] [CrossRef]

7) Ng L, Perich D, Burnett A, et al.: Self-reported prevalence, pain intensity and risk factors of low back pain in adolescent rowers. J Sci Med Sport, 2014, 17: 266-270. [Medline] [CrossRef]

8) Talasz H, Kremser C, Kofler M, et al.: Phase-locked parallel movement of diaphragm and pelvic floor during breathing and coughing-a dynamic MRI investigation in healthy females. Int Urogynecol J Pelvic Floor Dysfunct, 2011, 22: 61-68. [Medline] [CrossRef]

9) Lee CW, Hwangbo K, Lee IS: The effects of combination patterns of proprioceptive neuromuscular facilitation and ball exercise on pain and muscle activity of chronic low back pain patients. J Phys Ther Sci, 2014, 26: 93-96. [Medline] [CrossRef]

10) Madill SJ, Harvey MA, McLean L: Women with SUI demonstrate motor control differences during voluntary pelvic floor muscle contractions. Int Urogynecol J Pelvic Floor Dysfunct, 2009, 20: 447-459. [Medline] [CrossRef]

11) Imai A, Kaneoka K, Okubo Y, et al.: Trunk muscle activity during lumbar stabilization exercises on both a stable and unstable surface. J Orthop Sports Phys Ther, 2010, 40: 369-375. [Medline] [CrossRef]

12) Kong YS, Cho YH, Park JW: Changes in the activities of the trunk muscles in different kinds of bridging exercises. J Phys Ther Sci, 2013, 25: 1609-1612. [Medline] [CrossRef]

13) Kim ER, Kang MH, Kim YG, et al.: Effects of a home exercise program on the self-report disability index and gait parameters in patients with lumbar spinal stenosis. J Phys Ther Sci, 2014, 26: 305-307. [Medline] [CrossRef]

14) Urquhart DM, Hodges PW, Allen TJ, et al.: Abdominal muscle recruitment during a range of voluntary exercises. Man Ther, 2005, 10: 144-153. [Medline] [CrossRef]

15) Stevens VK, Coorevits PL, Bouche KG, et al.: The influence of specific training on trunk muscle recruitment patterns in healthy subjects during stabilization exercises. Man Ther, 2007, 12: 271-279. [Medline] [CrossRef]

16) O’Sullivan PB: Lumbar segmental 'instability': clinical presentation and specific stabilizing exercise management. Man Ther, 2000, 5: 2-12. [Medline] [CrossRef]

17) Cho M: The effects of bridge exercise with the abdominal drawing-in maneuver on an unstable surface on the abdominal muscle thickness of healthy adults. J Phys Ther Sci, 2015, 27: 255-257. [Medline] [CrossRef]

18) Macedo LG, Latimer J, Maher CG, et al.: Effect of motor control exercises versus graded activity in patients with chronic nonspecific low back pain: a randomized controlled trial. Phys Ther, 2012, 92: 363-377. [Medline] [CrossRef]

19) Urquhart DM, Barker PJ, Hodges PW, et al.: Regional morphology of the transversus abdominis and obliquus internus and externus abdominis muscles. Clin Biomech (Bristol, Avon), 2005, 20: 233-241. [Medline] [CrossRef]

20) Marshall PW, Desai I, Robbins DW: Core stability exercises in individuals with and without chronic nonspecific low back pain. J Strength Cond Res, 2011, 25: 3404-3411. [Medline] [CrossRef]

21) Ki C, Heo M: Effects of feedback forced breathing exercise on the weight lifting and thoracic stabilization of chronic low back pain patients. J Korea Entertain Ind Assoc, 2014, 8: 441-499. [CrossRef]

22) Ferreira PH, Ferreira ML, Maher CG, et al.: Changes in recruitment of transversus abdominis correlate with disability in people with chronic low back pain. Br J Sports Med, 2010, 44: 1166-1172. [Medline] [CrossRef]

23) Yoon TL, Cynn HS, Choi SA, et al.: Trunk muscle activation during different quadruped stabilization exercises in individuals with chronic low back pain. Physiother Res Int, 2015, 20: 126-132. [Medline] [CrossRef]

24) Niemistö L, Lahtinen-Suopanki T, Rissanen P, et al.: A randomized trial of combined manipulation, stabilizing exercises, and physician consultation compared to physician consultation alone for chronic low back pain. Spine, 2003, 28: 2185-2191. [Medline] [CrossRef]

25) Sung PS: Multifidi muscles median frequency before and after spinal stabilization exercises. Arch Phys Med Rehabil, 2003, 84: 1313-1318. [Medline] [CrossRef]

26) Kang JI, Jeong DK: The effect of lumbosacral stabilization exercise on ODI and gait velocity of patients with chronic low back pain. J Digit Policy Manage, 2013, 11: 1738-1916.

27) Son HH: The effects of stabilization exercise with abdominal breath on balance and oswestry disability index for low back pain patients. J Korean SocPhys Med, 2015, 10: 107-113. [CrossRef] 